\section{Micropropagation of Cypripedium formosanum Hayata through Axillary Buds from Mature Plants}

\author{
Yung-I Lee \\ Botany Department, National Museum of Natural Science, No 1, Kuan-Chien \\ Road, Taichung, Taiwan
}

Additional index words. micropropagation, rhizome, shoot multiplication, slipper orchids, tissue culture

\begin{abstract}
A micropropagation protocol for an endangered slipper orchid species, Cypripedium formosanum Hayata, through axillary buds from adult plants has been developed. The season of explant collection is crucial for the initial success of an aseptic culture. Explants collected in the middle of January gave the highest percentage of explant survival $(54.2 \%)$ and shoot-forming percentage $(41.7 \%)$. Of the two cytokinins tested, $\mathbf{N}^{6}$-benzyladenine (BA) was found to be superior to thidiazuron for normal shoot formation. The optimum result was obtained in quarter-strength Murashige and Skoog medium containing 22.2 or $44.4 \mu \mathrm{M}$ BA in which the cultures produced 6.3 and 7.1 shoots per explant with 10.6 to $11.7 \mathrm{~mm}$ average length after $90 \mathrm{~d}$ of culture. Regenerated shoots rooted for $60 \mathrm{~d}$ in the basal medium with $1 \mathrm{~g} \cdot \mathrm{L}^{-1}$ activated charcoal and $20 \mathrm{~g} \cdot \mathrm{L}^{-1}$ potato homogenate were ready for growth in pots. This is the first report on shoot multiplication in vitro from mature plants of Cypripedium that provides a reliable method for propagating the selected elites.
\end{abstract}

Cypripedium formosanum Hayata is a rare slipper orchid species endemic to Taiwan that has a pinkish single flower above fan-shaped leaves at the stem apex (Cribb, 1997; Lin, 1987). C. formosanum is one of the popular potted and perennial gardening plants. Usually, the rhizomes with dormant flower buds are collected in the winter, and buds bloom after bud breaking from dormancy. However, conventionally propagation by vegetative division of $C$. formosanum is time-consuming, because the rhizome usually produces only one shoot bud yearly. Therefore, a rapid, reliable protocol for propagation is required. Nevertheless, attempts to culture the slipper orchids (Cypripedium Linnaeus, Paphiopedilum Pfitzer, Phragmipedium Rolfe, and Selenipedium Rchb. F.) in vitro are still challenging (Arditti and Ernst, 1993; Stewart and Button, 1975). Recently, plant regeneration through seed-derived explants has been reported in Paphiopedilum (Chen et al., 2004; Huang et al., 2001; Lin et al., 2000) and Cypripedium (Lee and Lee, 2003; Shimura and Koda, 2004; Yan et al., 2006). In $C$. montanum Douglas ex Lindl., multiple shoots were successfully obtained from the seedling node cultures on the medium with 8.88 $\mu \mathrm{M} \mathrm{N}^{6}$-benzyladenine (BA) and $1.07 \mu \mathrm{M} 1$ naphthaleneacetic acid (Hoshi et al., 1994).

Received for publication 26 Jan. 2010. Accepted for publication 23 June 2010 .

This work was supported by grants from the National Museum of Natural Science.

I thank Mei-Fong Highland Experimental Farm (National Taiwan University) for maintaining the plant materials.

e-mail leeyungi@mail.nmns.edu.tw.

C. formosanum using explants from adult plants. The effects of timing for explant collection, BA and thidiazuron (TDZ) concentrations on shoot multiplication, and organic supplements on plantlet rooting were investigated.

\section{Materials and Methods}

Plant material, culture medium, and conditions. More than 10-year-old plants of C. formosanum were maintained in a greenhouse at Mei-Fong Highland Experimental Farm (2100 $\mathrm{m}$ above sea level) and were used as plant materials. The axillary buds of terminal shoot buds of rhizomes were used as the explant sources (Fig. 1A). Shoot buds were first washed with detergent and rinsed under running tap water for $1 \mathrm{~min}$ and then immersed in $70 \%(\mathrm{v} / \mathrm{v})$ ethanol for $10 \mathrm{~s}$ followed by immersion in $2 \%$ sodium hypochlorite solution for $20 \mathrm{~min}$. They were subsequently washed three times with sterile distilled water, and then the sheaths were removed to reveal the axillary buds (Fig. 1B). The axillary buds of terminal shoot buds were surface-sterilized again with a $0.5 \%$ sodium hypochlorite solution for $15 \mathrm{~min}$. After three rinses with sterile distilled water, the lateral buds were excised and used as the explants.

The basic culture medium was composed of the quarter-strength macroelements of Murashige and Skoog (MS) basal salts (Murashige and Skoog, 1962) with fullstrength microelements supplemented with 2 $\mathrm{mg} \cdot \mathrm{L}^{-1}$ glycine, $0.5 \mathrm{mg} \cdot \mathrm{L}^{-1}$ niacin, $0.5 \mathrm{mg} \cdot \mathrm{L}^{-1}$ pyridoxine $\mathrm{HCl}, 0.1 \mathrm{mg} \cdot \mathrm{L}^{-1}$ thiamine, 100 $\mathrm{mg} \cdot \mathrm{L}^{-1}$ myo-inositol, $20 \mathrm{~g} \cdot \mathrm{L}^{-1}$ sucrose (Sigma Chemical Co., St. Louis, MO), $1 \mathrm{~g} \cdot \mathrm{L}^{-1}$ tryptone (Merck KGaA, Darmstadt, Germany), and $2.2 \mathrm{~g} \cdot \mathrm{L}^{-1}$ Gelrite (Sigma Chemical Co.). The $\mathrm{pH}$ was adjusted to 5.7 with $1 \mathrm{~N} \mathrm{HCl}$ before autoclaving at $121{ }^{\circ} \mathrm{C}$ and $1.2 \mathrm{~kg} \cdot \mathrm{cm}^{-2}$ for $15 \mathrm{~min}$. The cultures were inoculated onto $10 \mathrm{~mL}$ solidified medium in $25 \times 100-\mathrm{mm}$ culture tubes and maintained at $26 \pm 2{ }^{\circ} \mathrm{C}$ under a 12/12-h photoperiod with daylight fluorescent lamps (20W; China Electric Co., Taipei, Taiwan) at a light intensity of 20 $\mu \mathrm{mol} \cdot \mathrm{m}^{-2} \cdot \mathrm{s}^{-1}$.

Seasonal influence on multiple shoot induction. To investigate the seasonal effect

Fig. 1. Plant materials and explants used to initiate in vitro culture. (A) The terminal shoot bud is in a dormant state with a floral bud inside. The arrow indicated the lateral bud. Bar $=10 \mathrm{~mm}$. (B) After surface sterilizing, the lateral bud was excised and used as the explants. Bar $=1 \mathrm{~mm}$.

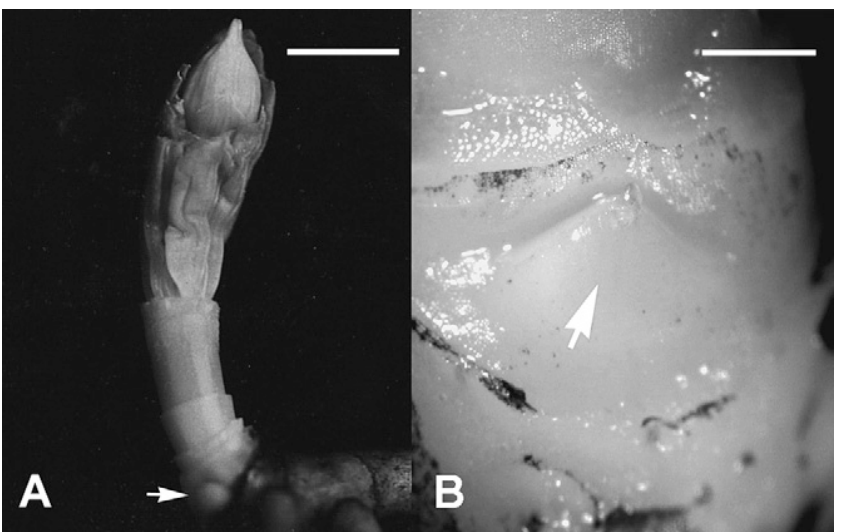


on the explant survival and multiple shoot formation, the explants were collected in the middle of January, April, July, and October for in vitro propagation. The culture medium of this experiment was composed of the basic culture medium with $4.44 \mu \mathrm{M}$ BA. The explants were subcultured every $30 \mathrm{~d}$ and the explant survival percentage, the shootforming percentage, and the mean shoot number per explant were recorded at $90 \mathrm{~d}$ of culture: explant survival percentage $=$ number of explant survival/number of explant cultured $\times 100 \%$; shoot-forming percentage $=$ number of explant survival with shoot formation/number of explant survival $\times$ $100 \%$.

Effect of cytokinins on shoot multiplication. To investigate the effect of cytokinins on the shoot multiplication, the explants collected in January were inoculated onto the basic medium with the cytokinins that consisted of different concentrations of BA at $0,4.44$, 22.2, and $44.4 \mu \mathrm{M}$ and TDZ at $0,0.45,4.54$, and $22.7 \mu \mathrm{M}$. The explants were subcultured every $30 \mathrm{~d}$; the mean shoot number per explant and the mean shoot length were recorded at 90 $\mathrm{d}$ of culture. The shoot number and length were measured under a stereomicroscope (Carl Zeiss AG, Jena, Germany) with a scale.

Effect of organic supplementss on rooting of plantlets. To investigate the effect of organic supplements on rooting of plantlets, shoots 10 to $5 \mathrm{~mm}$ in length were excised and cultured on the basic medium with $1 \mathrm{~g} \cdot \mathrm{L}^{-1}$ activated charcoal and supplemented with potato homogenate $\left(20\right.$ or $\left.50 \mathrm{~g} \cdot \mathrm{L}^{-1}\right)$ or banana homogenate $\left(20\right.$ or $50 \mathrm{~g} \cdot \mathrm{L}^{-1}$ ) as reported by Lee and Lee (2003). Under the stereomicroscope with a scale, the mean root number per plantlet and the mean root length were measured and recorded at $60 \mathrm{~d}$ of culture.

Statistical analysis. In these experiments, 12 replicates (one explant was planted in each culture tube) were taken for each treatment, and the experiments were repeated three times. All experiments were established in a completely randomized design and repeated three with 12 replicates per experiment and one explant per replicate. Data were subject to analysis of variance. Mean separation was achieved by Duncan's multiple range test (Duncan, 1955). The percentage data were arcsine-transformed.

\section{Results and Discussion}

The season of explant collection for in vitro culture is crucial (Fig. 2). The optimum explant survival $(54.2 \%)$ and shoot-forming percentage $(41.7 \%)$ were found in the explants collected in January. The explant survival and shoot-forming percentage decreased to $29.2 \%$ and $20.8 \%$, respectively, in the explants collected in October. For explants collected in April and July, the explant survival was the lowest $(8.3 \%$ and $4.2 \%)$ and shoot-forming percentage fell to zero. Explants collected in January and October produced near the same shoot number (Fig. 2C). In several perennial plants, seasonal influence of explant collection has been shown to

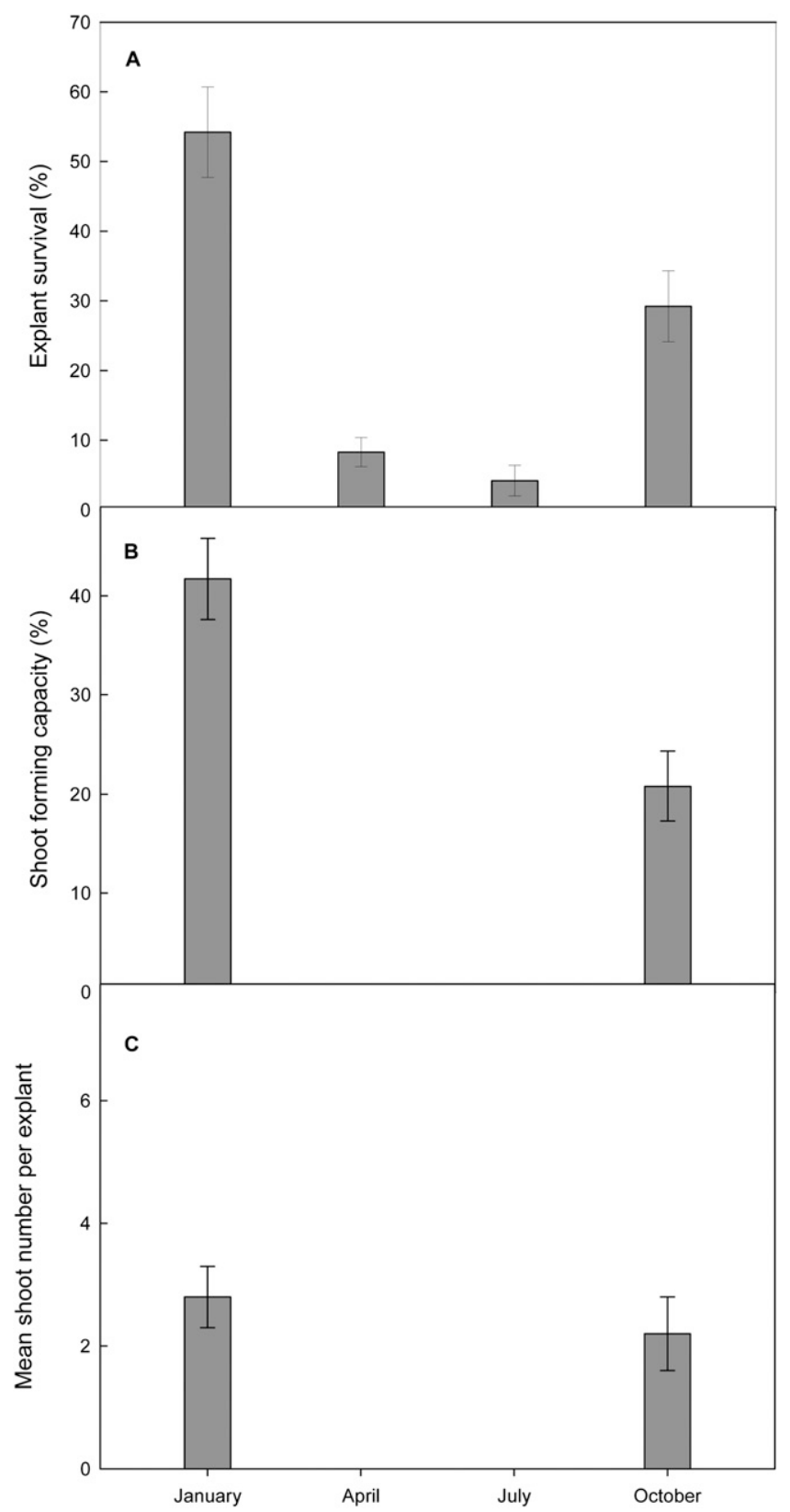

Fig. 2. Seasonal effect on (A) the explant survival percentage, (B) the shoot-forming percentage, and (C) the mean shoot number per explant of Cypripedium formosanum at quarter-strength Murashige and Skoog medium supplemented with $4.44 \mu \mathrm{M} \mathrm{N}^{6}$-benzyladenine. Explant survival percentage $=$ number of explant survival/number of explant cultured $\times 100 \%$; shoot-forming percentage $=$ number of explant survival with shoot formation/number of explant survival $\times 100 \%$. Data were recorded after $90 \mathrm{~d}$ of culture.

play an important role on aseptic culture establishment (Kartsonas and Papafotiou, 2007; Kumar et al., 2005). In tissue culture of Pleione formosana Hayata, an alpine orchid, the best response was achieved when shoot buds were harvested in winter and then stored at $5^{\circ} \mathrm{C}$ for $60 \mathrm{~d}$ (Chang and Lee, 1992). According to the report by Lee and Teng (1987), the endogenous gibberellins and indole-3-acetic acid levels increased dramatically in $P$. formosana corms after cold storage. Because most Cypripedium species inhabit temperate regions or high mountain areas with distinct seasonality, its growth depends on the changes of seasons (Cribb, 1997). In April, the new rhizome bud of $C$. formosanum begins to elongate as the plant blooms; in July, the rhizome is fully developed to its final length, whereas the terminal shoot bud is undergoing flower differentiation; in October, the terminal shoot bud is expanded and protrudes above the ground as the leaf has turned yellowish green; in the next January, the terminal shoot bud is in a dormant state, whereas the leaf withers away. Further studies on the changes of endogenous hormones of shoot buds in different seasons may help to clarify the role of seasonal influence on aseptic culture establishment.

The initial growth of shoot buds from original explants was not vigorous. After $\approx 60 \mathrm{~d}$ of culture, the multiple shoots began 
to form. Increasing the BA and TDZ concentrations resulted in higher shoot multiplication (Table 1). Higher BA concentrations (22.2 and $44.4 \mu \mathrm{M}$ ) induced 7.1 and 6.3 shoots per explant with mean shoot length of 10.6 and 11.4, respectively, after $90 \mathrm{~d}$ of culture (Fig. 3A). Successful reports on tissue culture from mature plants are limited in slipper orchids (Arditti and Ernst, 1993; Stewart and Button, 1975). In vitro multiplication of shoots of Paphiopedilum (a relative genus) was satisfactory in MS medium containing $444 \mu \mathrm{M}$ BA (Huang, 1988). In the present investigation, as compared with the $22.2 \mu \mathrm{M}$ BA treatment, shoot multiplication in the medium with $44.4 \mu \mathrm{M}$ BA was not higher. In our preliminary experiment, the inhibitory effect of a high concentration of BA (greater than $88.8 \mu \mathrm{M} \mathrm{BA}$ ) on shoot development was observed, suggesting that such a high level of BA is toxic to $C$. formosanum explants.

TDZ has shown significant effects to stimulate adventitious shoot formation in recalcitrant woody species; nevertheless, prolonged treatment with TDZ may cause abnormal shoot morphology (Lu, 1993). According to the reports of Cypripedium (Lee and Lee, 2003) and Paphiopedilum (Lin et al., 2000), TDZ in combination with 2, 4-D improved callus formation and in vitro morphogenesis. TDZ also promoted direct shoot bud formation from leaf segment explants of Paphiopedilum hybrids (Chen et al., 2004); however, in the other Paphiopedilum hybrids, TDZ inhibited the shoot proliferation (Huang et al., 2001). It is suggested that TDZ was necessary to induce the callus and bud formation from leaf segment explants of Paphiopedilum, but the shoot proliferation may only occur and develop normally when TDZ was at a lower concentration. In this study, although culture in the medium containing $22.7 \mu \mathrm{M}$ TDZ resulted in the highest shoot-forming number (12.5 shoots per explant), most shoot buds were stunted (Fig. 3B). On the contrary, the supplement of TDZ at $0.45 \mu \mathrm{M}$ produced less shoot number but had regular shoot growth. For root induction, the potato and banana homogenates promoted rooting in terms of both number and length of roots (Table 2). The organic supplements have been frequently used in orchid micropropagation, although the effect is complex and varied depending on different species and explants (Arditti and Ernst, 1993; Ernst, 1967). The results of this study indicated that the supplements of potato and banana homogenates improved rooting that was similar to our previous report (Lee and Lee, 2003). After $60 \mathrm{~d}$ of culture, the plantlets produced an average of five roots per plantlet $6.4 \mathrm{~cm}$ in length, which were ready for ex vitro transfer (Fig. 3C).

In conclusion, this study describes a successful procedure for in vitro clonal propagation of $C$. formosanum through axillary buds from mature plants. Collecting the explants in January for inoculation gives the best survival and shoot-forming percentage. In this procedure, an axillary bud could pro-

Table 1. The effects of $\mathrm{N}^{6}$-benzyladenine (BA) and thidiazuron (TDZ) concentrations on shoot multiplication of Cypripedium formosanum. ${ }^{\mathrm{z}}$

\begin{tabular}{cccc}
\hline BA $(\mu \mathrm{M})$ & TDZ $(\mu \mathrm{M})$ & Mean shoot number & Mean shoot length $(\mathrm{mm})$ \\
\hline 0 & 0 & $1.1 \mathrm{~d}^{\mathrm{y}}$ & $12.1 \mathrm{a}$ \\
4.44 & 0 & $2.8 \mathrm{c}$ & $10.2 \mathrm{a}$ \\
22.2 & 0 & $7.1 \mathrm{~b}$ & $10.6 \mathrm{a}$ \\
44.4 & 0 & $6.3 \mathrm{~b}$ & $11.4 \mathrm{a}$ \\
0 & 0.45 & $3.2 \mathrm{c}$ & $8.6 \mathrm{~b}$ \\
0 & 4.54 & $9.7 \mathrm{ab}$ & $5.2 \mathrm{c}$ \\
0 & 22.7 & $12.5 \mathrm{a}$ & $4.9 \mathrm{c}$ \\
\hline
\end{tabular}

${ }^{2}$ Data were recorded after $90 \mathrm{~d}$ of culture.

${ }^{y}$ Means having the same letter in a column are not significantly different by Duncan's multiple range test at $P<0.05$ (Duncan, 1955).

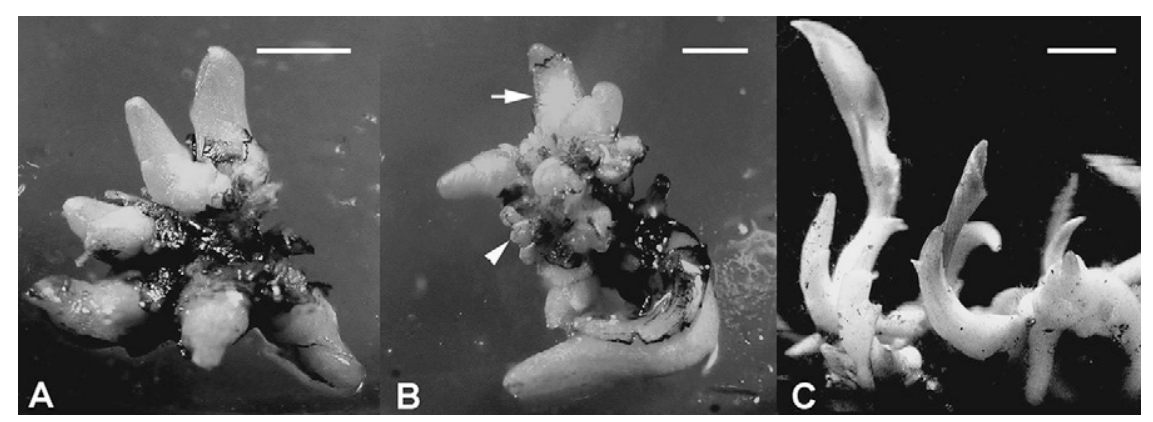

Fig. 3. In vitro clonal propagation of Cypripedium formosanum: (A) Normal shoot formation on quarterstrength Murashige and Skoog (MS) medium containing $44.4 \mu \mathrm{M} \mathrm{N} \mathrm{N}^{6}$-benzyladenine after $90 \mathrm{~d}$ of culture. Bar $=5 \mathrm{~mm}$. (B) Both normal (arrow) and stunted (arrowhead) shoot formation on quarterstrength MS medium containing $22.7 \mu \mathrm{M}$ thidiazuron after $90 \mathrm{~d}$ of culture. Bar $=5 \mathrm{~mm}$. (C) Root formation of excised shoots grown on quarter-strength MS medium with $1 \mathrm{~g} \cdot \mathrm{L}^{-1}$ activated charcoal and $20 \mathrm{~g} \cdot \mathrm{L}^{-1}$ potato homogenate after $60 \mathrm{~d}$ of transfer. $\mathrm{Bar}=10 \mathrm{~mm}$.

Table 2. The effect of potato and banana homogenate on plantlet rooting of Cypripedium formosanum. ${ }^{\mathrm{z}}$

\begin{tabular}{lccc}
\hline Organic supplements & $\left(\mathrm{g} \cdot \mathrm{L}^{-1}\right)$ & Mean root number per plantlet & Mean root length $(\mathrm{cm})$ \\
\hline Control $^{\mathrm{y}}$ & & $3.7 \mathrm{~b}^{\mathrm{x}}$ & $4.2 \mathrm{~b}$ \\
Potato homogenate & 20 & $5.0 \mathrm{a}$ & $6.4 \mathrm{a}$ \\
& 50 & $4.5 \mathrm{ab}$ & $6.2 \mathrm{a}$ \\
Banana homogenate & 20 & $4.3 \mathrm{ab}$ & $5.4 \mathrm{ab}$ \\
& 50 & $4.2 \mathrm{ab}$ & $5.1 \mathrm{ab}$ \\
\hline
\end{tabular}

${ }^{2}$ Data were recorded after $60 \mathrm{~d}$ of culture.

${ }^{y}$ The basic medium with $1 \mathrm{~g} \cdot \mathrm{L}^{-1}$ activated charcoal lacking organic supplements served as control.

${ }^{x}$ Means having the same letter in a column are not significantly different by Duncan's multiple range test at $P<0.05$ (Duncan, 1955).

duce approximately six vigorous shoots on the basal medium with $22.2 \mu \mathrm{M}$ BA after 90 $\mathrm{d}$ of culture. Once the culture establishes, the aseptic shoots can be excised and subcultured on the same medium for further multiplication. Although the growth of multiple shoots was slow, the technique described here makes it possible to propagate the selected elites in quantity for the horticultural market. This protocol could be also valuable for the ex situ conservation of elite germplasm of Cypripedium species.

\section{Literature Cited}

Arditti, J. and R. Ernst. 1993. Micropropagation of orchids. Wiley, New York, NY.

Chang, Y.C. and N. Lee. 1992. Tissue culture of Pleione formosana Hayata. J. Chinese Soc. Hort. Sci. 38:80-90.

Chen, T.Y., J.T. Chen, and W.C. Chang. 2004. Plant regeneration through direct shoot bud formation from leaf cultures of Paphiopedilum orchids. Plant Cell Tiss. Org. Cult. 76:11-15.

Cribb, P.J. 1997. The genus Cypripedium. Timber Press, Portland, OR.
Duncan, D.B. 1955. Multiple range and multiple F test. Biometrics 11:1-42.

Ernst, R. 1967. Effect of select organic nutrient additives on growth in vitro of Phalaenopsis seedlings. Amer. Orchid Soc. Bull. 36:386394.

Evers, P.W., J. Donkers, A. Prat, and E. Vermeer. 1988. Micropagation of forest trees through tissue culture. Pudoc, Wageningen, The Netherlands.

Hoshi, Y., K. Kondo, and S. Hamatani. 1994. In vitro seed germination of four Asiatic taxa of Cypripedium and notes on the nodal micropropagation of American Cypripedium montanum. Lindelyana 9:93-97.

Huang, L.C. 1988. A procedure for asexual multiplication of Paphiopedilum in vitro. Amer. Orchid Soc. Bull. 57:274-277.

Huang, L.C., C.J. Lin, C.I. Kuo, B.L. Kuang, and T Murashige. 2001. Paphiopedilum cloning in vitro. Sci. Hort. 91:111-121.

Kartsonas, E. and M. Papafotiou. 2007. Mother plant age and seasonal influence on in vitro propagation of Quercus euboica Pap., an endemic, rare and endangered oak species of Greece. Plant Cell Tiss. Org. Cult. 90:111116. 
Kumar, R., K. Sharma, and V. Agrawal. 2005. In vitro clonal propagation of Holarrhena antidysenterica (L.) Wall. through nodal explants from mature trees. In Vitro Cell. Dev. Biol. Plant 41:137-144.

Lee, N. and W.L. Teng. 1987. Endogenous growth promoter and inhibitor levels in Pleione formosana corms. Acta Hort. 205:225-231.

Lee, Y.I. and N. Lee. 2003. Plant regeneration from protocorm-derived callus of Cypripedium formosanum. In Vitro Cell. Dev. Biol. Plant 39: 475-479.
Lin, T.P. 1987. Native orchids of Taiwan. Vol. 3. Southern Materials Ctr., Taipei, Republic of China.

Lin, Y.H., C. Chang, and W.C. Chang. 2000. Plant regeneration from callus culture of a Paphiopediulm hybrid. Plant Cell Tiss. Org. Cult. 62:2125.

Lu, C.Y. 1993. The use of thidiazuron in tissue culture. In Vitro Cell. Dev. Biol. Plant 29:92-96.

Murashige, T. and F. Skoog. 1962. A revised medium for rapid growth and bioassays with tobacco tissue cultures. Physiol. Plant. 15:473-479.
Shimura, H. and Y. Koda. 2004. Micropropagation of Cypripedium macranthos var. rebunense through protocorm-like bodies derived from mature seeds. Plant Cell Tiss. Org. Cult. 78:273-276.

Stewart, J. and J. Button. 1975. Tissue culture studies in Paphiopedilum. Amer. Orchid Soc. Bull. 44:591-599.

Yan, N., H. Hu, J.L. Huang, K. Xu, H. Wang, and Z.K. Zhou. 2006. Micropropagation of Cypripedium flavum through multiple shoots of seedlings derived from mature seeds. Plant Cell Tiss. Org. Cult. 84:114-118. 